\title{
Anabases
}

ANABASES Traditions et réceptions de l'Antiquité

$8 \mid 2008$

Varia

\section{Nicolas RICHER (dir.), Xénophon et Sparte}

\section{Pascal Payen}

\section{OpenEdition \\ Journals}

Édition électronique

URL : http://journals.openedition.org/anabases/263

DOI : 10.4000/anabases.263

ISSN : 2256-9421

\section{Éditeur}

E.R.A.S.M.E.

\section{Édition imprimée}

Date de publication : 1 octobre 2008

Pagination : 302-304

ISSN : 1774-4296

\section{Référence électronique}

Pascal Payen, "Nicolas richer (dir.), Xénophon et Sparte ", Anabases [En ligne], 8| 2008, mis en ligne le 01 juillet 2011, consulté le 22 septembre 2020. URL : http://journals.openedition.org/anabases/263 ; DOI : https://doi.org/10.4000/anabases.263

Ce document a été généré automatiquement le 22 septembre 2020.

(c) Anabases 


\title{
Nicolas RICHER (dir.), Xénophon et Sparte
}

\author{
Pascal Payen
}

\section{RÉFÉRENCE}

Nicolas RICHER (dir.), Xénophon et Sparte, Colloque international organisé à l'École normale supérieure Lettres et Sciences humaines (Lyon), les 15, 16 et 17 juillet 2006, Ktèma, 32 (2007), p. 293-456

65 euros / ISSN 0221-5896.

1 Il est inhabituel de faire la recension d'un dossier paru dans une revue. Si l'on fait exception ici, c'est en raison de la cohérence thématique et du volume de l'ensemble (dix contributions), issu d'un colloque international organisé par Nicolas Richer (les travaux issus du colloque et non publiés ici le seront dans un volume intitulé Xenophon and Sparta, à The Classical Press of Wales).

Cette publication participe du renouveau des études consacrées à Xénophon. Loin de l'image traditionnelle d'un historien confus d'une époque elle-même troublée, annonçant, après le désastre de la guerre du Péloponnèse, le déclin proche et irrémédiable de la Cité grecque, Xénophon est considéré par les contributeurs comme une source de grande valeur sur Sparte, comme un penseur qui a puissamment contribué à faire évoluer l'image de la cité, et comme l'auteur d'une œuvre qui possède une puissante unité de pensée, quels que soient le genre des traités qui la composent, l'occasion ou le contexte de communication dans lesquels ils s'inscrivent, le public auquel ils sont destinés.

3 Les trois premières contributions sont consacrées à la République des Lacédémoniens. Ephraïm David ("Xénophon et le mythe de Lycurgue") montre que la réflexion de Xénophon constitue une étape essentielle dans le développement de la légende. Alors qu'Hérodote fait de lui le fondateur des institutions et du " bel ordre » (eunomia) de la cité, Xénophon lui attribue l'ensemble des normes et des vertus eugéniques, les 
préceptes et l'organisation qui règle tous les aspects de la vie des citoyens; il est « un véritable héros culturel pluridisciplinaire"(p.303). Xénophon, en ce sens; fait profondément évoluer le mythe, en imposant l'image d'un Lycurgue omniscient et donc, aussi, d'une Sparte conçue " gymnase de vertus » (p.303, 308). C'est à partir de l'analyse de Xénophon que le mythe de Lycurgue et celui d'une Sparte idéale se confondent et font antithèse avec une autre construction, celle de la Sparte décadente. Les deux contributions suivantes étudient un passage problématique du même traité. Annalisa Paradiso examine la célèbre description $(2,9)$ du vol commis par de jeunes garçons à l'autel d'Artémis Orthia. L'interprétation consacrée considère qu'il s'agit de fromages (tyrous / tupoú), alors que trois bons manuscrits transmettent la variante pyrous / זupoú. Après avoir analysé toutes les connections qu'entretient l'anthropologie spartiate avec le fromage et avec le blé, l'auteur considère qu'il s'agit de deux leçons également valables et que tout éditeur se doit de le mentionner dans l'apparat critique. Jean Ducas, d'une manière proche, analyse le "système » sur lequel repose le chapitre IV, 1-6, consacré aux rivalités qui animent les hèbôntes, catégorie d'âge tout juste sortie du système éducatif, pour entrer dans le groupe des hippeis (cavaliers).

4 Les trois études suivantes permettent de mesurer l'apport de Xénophon à notre connaissance des institutions et des évolutions de Sparte. Nikos Birgalias ("La gérousia et les gérontes de Sparte"), en exposant le dossier complexe de la constitution et de l'influence de la Gérousia dans le jeu politique qui l'oppose aux Rois et aux Ephores, tend à montrer que les gérontes étaient choisis parmi les membres des deux familles royales (mais les sources retenues dans cette étude ne paraissent pas provenir principalement de Xénophon). Au livre IV des Helléniques, Xénophon devient presque notre seule source sur certains épisodes oubliés, parce que peu glorieux, de la guerre de Corinthe, où les pillages et les exactions contreviennent aux "lois de la guerre " (César Fornis, “Campañas espartanas olvidadas"). Pierre Pontier ("Xénophon, Sparte, et Phlionte") montre que les deux longs exposés consacrés, dans les Helléniques, à l'histoire politique de Phlionte, petite cité du nord du Péloponnèse, respectivement après la paix d'Antalcidas, vers 381 (V, 3, 10-25), et après la bataille de Leuctres, entre 369 et 366 (VII, 2), constituent une réflexion politique nuancée sur le comportement des cités, dont les valeurs changent de sens en fonction de leur taille.

5 Les quatre dernières études envisagent les représentations dont Sparte, ses institutions, ses mœurs peuvent être l'objet dans les œuvres de Xénophon. Gianluca Cuniberti ("Per chi scrive Senofonte? Il ruolo dei Lacedemoni nella produzione e ricezione delle opere di Senofonte") analyse les conséquences du fait qu'une partie importante des traités de Xénophon a pour destinataires les Lacédémoniens. Dans une perspective d'analyse proche, Giovanna Daverio Rocchi souligne que les Helléniques offrent la représentation d'une Sparte plus ouverte, plus "panhellénique ", que la République des Lacédémoniens et l'Agésilas. La contribution de Nicolas Richer s'attache, elle aussi, à saisir les nuances qui s'attachent à la représentation d'un " modèle lacédémonien " dans les traités non historiques de Xénophon et notamment dans les Mémorables. La Cyropédie, non prise en compte dans l'étude précédente, fait l'objet de la contribution de Vincent Azoulay ("Sparte et la Cyropédie: du bon usage de l'analogie") qui analyse le jeu d'interférences complexes et nuancées entre le système politique perse et la politeia spartiate. Même si la constitution perse est une sorte d'« idéal-type d'inspiration laconienne ", le référent spartiate n'est pas le seul; d'autres régimes 
oligarchiques sous-tendent la description de Xénophon et attestent par là l'étendue et la complexité de sa culture et de sa réflexion politiques.

6 De ces études, presque toutes pourvues d'une bibliographie, mais dont la richesse aurait exigé également une série d'indices (certes délicats à obtenir dans une revue), il ressort - faut-il encore le redire? - que Xénophon mérite d'être analysé à l'égal d'un Thucydide, dans des perspectives qui croisent approches historique et historiographique, et qui fassent droit à la complexité d'une vie et d'une pensée, en un temps (fin du v siècle et première moitié $d u \mathrm{IV}^{\mathrm{e}}$ siècle avant $\mathrm{J}$.-C.) de mutations dans les rapports entre les cités et dans la construction de ce que l'on peut appeler, par un anachronisme revendiqué, un nouvel ordre international.

\section{AUTEURS}

PASCAL PAYEN

Université de Toulouse (UTM)

payen@univ-tlse2.fr 